Science of The Total Environment, Volumes 512-513, 15 April 2015, Pages 287-295

Published by Elsevier. This is the Author Accepted Manuscript issued with:

Creative Commons Attribution Non-Commercial No Derivatives License (CC:BY:NC:ND 3.0).

\title{
Better by design: business preferences for environmental regulatory reform
}

Christopher M. Taylor ${ }^{1}$, Simon J.T. Pollard ${ }^{1}$, Sophie A. Rocks and Andrew J. Angus ${ }^{2}$

Cranfield University, ${ }^{1}$ Institute for Environment, Health, Risk and Futures and ${ }^{2}$ School of Management, Cranfield, Bedfordshire, MK43 0AL, UK

*Corresponding author: S.J.T. Pollard, Cranfield University, Cranfield, Bedfordshire, UK, MK43 0AL; email: s.pollard@ cranfield.ac.uk; Telephone: +44 (0)1234 754101

\section{Highlights}

- Cross-sectoral business preferences are reported on the direction of regulatory reform

- Business support for a tailored, but coherent mix of regulatory instruments is offered

- Analytical, institutional and political features need incorporating into reform programmes

- Closer business engagement during the transition to regulatory reform is called for

\section{Graphical abstract}

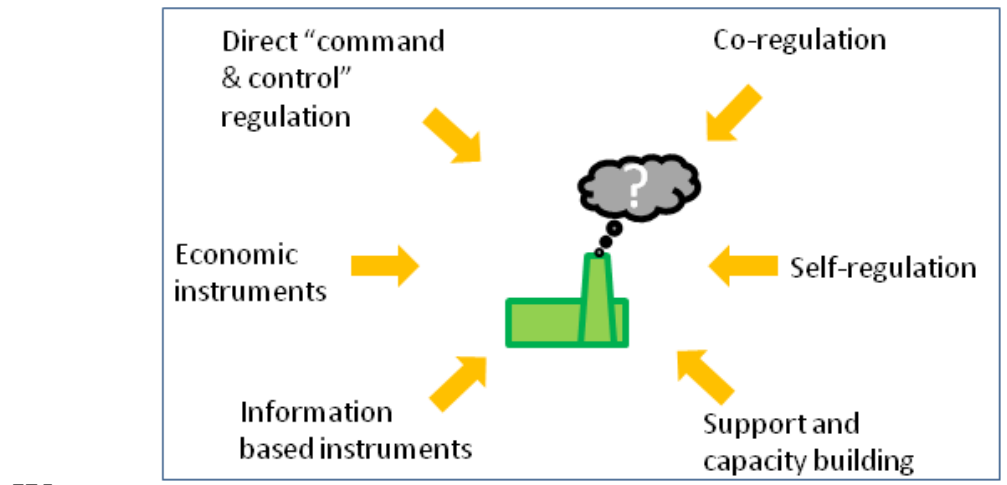

ABSTRACT

present the preferences

for environmental regulatory reform expressed by $30 \mathrm{UK}$ businesses and industry bodies from 5 sectors. While five strongly preferred voluntary regulation, seven expressed doubts 
about its effectiveness, and 18 expressed no general preference between instrument types. Voluntary approaches were valued for flexibility and lower burdens, but direct regulation offered stability and a level playing field. Respondents sought regulatory frameworks that: are coherent; balance clarity, prescription and flexibility; are enabled by positive regulatory relationships; administratively efficient; targeted according to risk magnitude and character; evidence-based and that deliver long-term market stability for regulatees. Anticipated differences in performance between types of instrument can be undermined by poor implementation. Results underline the need for policy makers and regulators to tailor an effective mix of instruments for a given sector, and to overcome analytical, institutional and political barriers to greater coherence, to better coordinate existing instruments and tackle new environmental challenges as they emerge.

\section{KEYWORDS}

environmental policy, regulation, regulatory reform, instrument selection 


\section{INTRODUCTION}

Over recent decades, governments in developed countries have put in place substantial bodies of environmental regulation, which have improved important elements of environmental quality and delivered significant benefits to society. This period has also seen sustained government effort to reform regulation, to reduce costs to business and enable economic growth. One focus of regulatory design and reform has been the choice of regulatory instrument (e.g. direct regulation, taxes, self-regulation); others include improving administrative efficiency (e.g. through simplifying compliance processes) and improving coherence (e.g. through integrated permits). Policy makers and regulators may choose to engage with industry to understand calls for regulatory reform, identify where problems lie and seek ideas for improvement. However, business views on regulatory reform are rarely explored directly by researchers. This study aims to address this gap by characterising the dimensions of reforms sought by a sample of business representatives.

Today governments can choose from a wide range of policy or regulatory instruments to protect or enhance the environment (Table 1). Here, the term "regulation" includes government and (non-state) governance (Gunningham and Sinclair, 1999) and "instruments" means the component parts of regulation (Taylor et al., 2012). 
Table 1. Instruments available to policy makers and regulators (Taylor et al., 2012)

\begin{tabular}{|l|l|}
\hline Type & Variant \\
\hline Direct "command and control" regulation & Ambient pollution requirements \\
\cline { 2 - 2 } & Input restrictions and output quotas \\
\cline { 2 - 2 } & Non-transferable emission licences \\
\cline { 2 - 2 } & Technology controls \\
\cline { 2 - 2 } & Zoning/ location controls \\
\hline Economic instruments & Taxes and subsidies \\
\cline { 2 - 2 } & Tradable rights \\
\cline { 2 - 2 } & Payments \\
\hline \multirow{5}{*}{ Co-regulation and self-regulation } & Targeted information provision \\
\cline { 2 - 2 } & Naming and shaming/faming \\
\cline { 2 - 2 } & Registration, labelling and certification \\
\hline & Voluntary regulation \\
\cline { 2 - 2 } & Covenants and negotiated agreements \\
\cline { 2 - 2 } & Private corporate regulation \\
\cline { 2 - 2 } & Private professional regulation \\
\cline { 2 - 2 } & Self-regulation \\
\cline { 2 - 2 } & Civic regulation \\
\hline \multirow{5}{*}{ Support and capacity building } & Research and knowledge generation \\
\cline { 2 - 2 } & Demonstration projects/ knowledge diffusion \\
\cline { 2 - 2 } & Network building and joint problem solving \\
\hline
\end{tabular}

Instruments are compared on the basis of their effectiveness in achieving intended outcomes (e.g. protecting environmental water quality, reducing atmospheric pollution, or resource consumption) and the efficiency, and fairness, with which they do so. While direct regulation has delivered significant improvements, it has been criticised for poor efficiency compared to alternatives that offer greater flexibility to business on how to achieve environmental objectives (Gunningham and Sinclair, 1999). Governments use these alternatives to harness the effect of social forces on business and citizen behaviour; such as consumer choice, or the influence of businesses on one another through the value chain. Commentators describe this as a shift from "government" to "governance" (Jordan et al., 2005), while calling for the purposeful design of coherent mixes of instruments (Braathen, 2007; Gunningham and Sinclair, 1999; Howlett and Rayner, 2007). A growing literature examines the performance of different types of instrument, typically founded in economics, though we contend that expost evaluations assessing instrument effectiveness are frequently lacking (Taylor et al., 2012). 
Regulation should be risk-informed, so that resources are targeted for maximum impact. Risk analysis scholars have examined governments' characterisation and prioritisation of strategic risks, (e.g. public exposure to engineered nanomaterials, the spread of foot and mouth disease, and flooding (Prpich et al., 2011)) and regulatory agencies' riskbased regulation for different industries, businesses and sites (Gouldson et al., 2009). A substantial literature examines the enforcement strategies of government agencies, including advice and persuasion, rules and deterrence, smart, risk-based or meta-regulation (Gunningham, 2011), the deployment of which, in concert, is a "regulatory craft" (Sparrow, 2008, 2000). Research exploring the role of personal interactions between regulators and the regulated is more limited (May and Winter, 1999; Pautz and Wamsley, 2012; Sevä and Jagers, 2013; Sparrow, 2008).

There is a developing international consensus on how governments should design and manage regulation to optimise performance. The Organisation for Economic Co-operation and Development (OECD) recommends governments (i) commit to a "whole-of-government" policy for regulatory quality; (ii) adhere to principles of open government; (iii) establish oversight institutions; (iv) integrate regulatory impact assessment and consider means other than regulation; (v) review the stock of regulation; (vi) report on regulatory performance; (vii) have consistent policy covering the role and functions of regulatory agencies; (viii) ensure effectiveness of regulatory agencies and the legal system; (ix) apply risk assessment, management and communication strategies; (x) promote coherence; (xi) foster regulatory management capacity; and (xii) cooperate internationally (OECD, 2012). National governments have pursued broad reforms. The Dutch Administrative Burden Reduction Programme, considered a world leader by the World Bank Group (Ladegaard et al., 2007), included a $25 \%$ burden reduction target, linked reform to the budgetary cycle and established an independent monitoring body (Actal, 2013). In the US, Executive Order (EO) 13563 
(Obama, 2011a) provides principles for improving regulation and regulatory review, while EO 13576 (Obama, 2011b) commits the Federal government to ongoing improvements in efficiency. In response, the US Environmental Protection Agency has established a rolling programme of reviews for existing regulations (US Environmental Protection Agency, 2014). In the UK, the 'Red Tape Challenge' (Cabinet Office, 2013) seeks to reduce burdens by improving or removing regulations. The UK government has a stated preference (Department for Business Innovation and Skills, 2013a) for alternatives to direct regulation across all policy areas and requires alternatives to be considered by policy makers (Department for Business Innovation and Skills, 2013b). Governments have also pursued regulatory reform to improve policy integration. The Swedish Environmental Code consolidated fragmented regulation, implemented new processes and institutions, and provided a platform for further improvement (OECD, 2004). European Union reforms, intended to improve integration, include the Integrated Pollution Prevention and Control (IPPC) Directive for controlling emissions from installations through permitting, leading to the Industrial Emissions Directive (European Parliament, 2010); and consolidation of chemicals regulation under the Registration, Evaluation, Authorisation and restriction of Chemicals (REACH) Regulation (European Commission, 2013).

While these initiatives attempt to rationalise the considerable stock of regulation, significant challenges remain. Scholars note the focus has moved from local or regional concerns such as smog and eutrophic rivers, to broader systemic issues such as climate change; and from immediate visible impacts to those with diffuse or delayed consequences. The science base has revealed the interconnectedness of environmental pressures (Rayner, 2006). New institutions of representative democracy imbued with regulatory authority to track new issues will be required to tackle global environmental concerns (Rayner, 2006) and ensure realistic courses of local and international action (Rayner, 2010). To improve the 
quality of this debate and guide policy staff on how to target regulatory reform effort, better evidence on what instruments have and could work when, with whom, and why is required. This is intensified by the need to respond to strong pressures for regulatory reform in developed nations attempting to recover from recent economic stagnation and concerned for their international competitiveness. The business community is an important source, although their views will inevitably by partial and should be balanced with voices of other stakeholder groups. Given the costs of regulation for business, one might hypothesise that business would argue for less regulation, which could undermine environmental protection, and limit the scope for alternatives that place greater responsibility in their hands. This study explores how businesses may respond to regulatory reform: 1) what arguments are made for the suitability of different forms of regulation?; 2) what other priorities for reform are emphasised?; and 3) what do these responses imply for future regulatory reform programmes?

\section{METHODS}

A multi-case study approach was adopted, employing semi-structured interviews with senior business representatives and executive representatives of trade bodies with an intimate understanding of their sector. This approach has been widely used for testing and extending theory; each case analogous to an individual experiment (Yin, 2009). Semi-structured interviews, averaging 1 hour in length, allowed respondents to reveal opinions and their attending explanations (Miles and Huberman, 1994). Respondents were presented with a typology of instruments (Table 1, with additional explanation), invited to comment on whether it included the main forms of regulation of which they were aware, to provide examples of regulations that worked well, or less well, and explain why, and comment on the need for regulatory reform. Five industries spanned a range of environmental regulations and 
risk: (i) construction and construction products; (ii) food and agriculture; (iii) personal care products; (iv) waste management and (v) water collection, treatment, supply and management (Table SI1). Interviews ( $\mathrm{n}=30)$ were conducted between January and June 2013, this sample size deemed sufficient given the organisational and representational roles that the highlyexperienced interviewees were in; given their depth of knowledge of the regulatory reform agenda; and mirroring methods deployed in similar appraisals from the policy literature where the views of a diverse set of interviewees are explored on a tightly scoped question set (e.g. see Tribbia and Moser, 2008). A cross section of business sectors of differing maturity was explored; these sectors representing experience across a variety of approaches to the regulation of risk, including those with an established convention in the use of industry codes and standards (construction); those with extended supply chains and with international standards in place (food and agriculture, personal care products); those where formalised, regulatory risk assessment played a long established role (personal care products, to an extent waste management) and those in transition towards formalised enterprise risk management (e.g. water, waste management). The rationale was to capture views from sectors with differing levels of risk management maturity, philosophies of approach to managing regulatory risk and that had been regulated using a range of tools from the taxonomy we have described previously (Taylor et al., 2012, 2013).

Organisations that had previously contributed to a regulatory reform programme were invited to participate under a covering letter explaining that the research was being undertaken independently. These cases were supplemented with a small number of additional organisations, to provide a range of contexts in which theories concerning environmental regulation could be developed and tested. Thirty-four interviewees from 30 organisations were interviewed in depth. Interviews were transcribed verbatim, except in one case where written notes were taken and validated with the respondent. Transcripts and notes were 
iteratively coded using NVIVO ${ }^{\text {TM }}$ Computer Assisted Qualitative Data Analysis Software (CAQDAS) (Bazeley, 2007). Transcripts were initially tagged according to recurring words or themes (e.g. "risk", "clarity") to allow the full breadth of concepts discussed to emerge from the data. These were then grouped into major explanatory themes (Miles and Huberman, 1994), which in turn were refined and summarised, while recognising the author's "theoretical sensitivity" (Kelle, 2005) to prior research (Taylor et al., 2012, 2013). Detailed data tables are provided in the Supporting Information (SI).

\section{RESULTS AND DISCUSSION}

Perhaps the most comprehensive account of the maturity and capacity of larger regulatory firms within a sector to respond to the new regulatory agenda is offered by Gunningham and Sinclair in "Leaders and Laggards" (Gunningham and Sinclair, 2002) . Many of their conclusions still hold and, in brief, these authors point to the importance of purposeful regulatory design; the effectiveness of a combined mix of instruments for large enterprises, rather than a one-size-fits-all approach; a fit-for-purpose approach to regulatory design and we believe the character of the risk (e.g. Sparrow, 2008) to be essential here; and the onward need for a judicial requirement for command and control as a backstop against free-riders. In the context of this prior art, we are concerned here in the next level of discussion, in the UK context, of how these generalised facets might play out across the sectors studied.

\section{Industry views on the suitability of regulatory instruments}

Respondents were shown a typology of regulatory instruments (constructed from prior research (Taylor et al., 2012) and tested with policy makers (Taylor et al., 2013)) and asked whether they considered it comprehensive. Their comments (Table SI2) provide further evidence that, with refinement, this typology provides a sound basis for the full range of 
instruments available to policy makers and regulators. Respondents' views on the suitability and performance of different forms of regulation were diverse (Table SI3). Respondents from 18 organisations did not show a clear preference between instrument types; instead, seeing merit in a purposeful mix of types depending on circumstances. Seven expressed scepticism about the effectiveness of voluntary and self-regulation, arguing that direct regulation was necessary to tackle poor environmental performance within their sector, nationally or internationally, so to achieve a "level playing field". Five respondents favoured voluntary approaches over additional direct regulation for their flexibility and goodness of fit to industry characteristics, while some expressed concern that further direct regulation would risk undermining their international competitiveness, pushing small and medium-sized enterprises (SMEs) out of business. Comparison of views of respondents from the same sector (Table SI3, summarised in Table 2) hints at industry- and business-specific characteristics that may influence these preferences. 
Table 2. Comparison of views across sectors

\begin{tabular}{|c|c|}
\hline Sector & Summary of views expressed by respondents \\
\hline $\begin{array}{l}\text { Construction and } \\
\text { construction products }\end{array}$ & $\begin{array}{l}\text { Direct regulation argued for by large constructors, concerned that (smaller) competitors } \\
\text { and supply chain participants will not adopt voluntary approaches, leading to } \\
\text { reputational risks and an unlevel playing field. Beyond-compliance behaviour driven } \\
\text { by customer demands (including government) among large constructors. Construction } \\
\text { materials respondents concerned about coherence of land management regulations. For } \\
\text { construction materials, direct regulation can provide easily implementable rules and a } \\
\text { framework within which other types of instrument, including industry led approaches, } \\
\text { have flourished. }\end{array}$ \\
\hline Food and agriculture & $\begin{array}{l}\text { Direct regulation necessary in some circumstances to protect public good, but must be } \\
\text { deployed with care to avoid undermining competitiveness. Large retailers driven more } \\
\text { by consumer demand for environmental performance beyond compliance, which exerts } \\
\text { pressure on the supply chain. Voluntary approaches strongly favoured by respondents } \\
\text { arguing the sector is heavily regulated by government and the supply chain, expressing } \\
\text { fears of direct regulation leading to economic disadvantage in international competition. }\end{array}$ \\
\hline $\begin{array}{l}\text { Personal care } \\
\text { products }\end{array}$ & $\begin{array}{l}\text { Views mixed, reflecting varying characteristics along supply chains. Direct regulation } \\
\text { via permits argued as optimal for industrial plants, and necessary to provide an } \\
\text { international level playing field. Sectoral track record of voluntary activity (e.g. on } \\
\text { HFCs, fragrance safety) demonstrates scope for self-regulation. }\end{array}$ \\
\hline Waste management & $\begin{array}{l}\text { Direct regulation has provided the platform on which the industry has developed. } \\
\text { Enforced direct regulation is required to tackle a minority of poor performing operators, } \\
\text { alongside earned recognition for more reputable operators. Voluntary approaches } \\
\text { appropriate for tackling resource efficiency and producer responsibility, where direct } \\
\text { regulation would be complex; but has proved unsuccessful in other areas. }\end{array}$ \\
\hline $\begin{array}{l}\text { Water management, } \\
\text { collection, treatment } \\
\text { and supply }\end{array}$ & $\begin{array}{l}\text { Direct regulation provides stability for investment planning, and necessary controls for } \\
\text { some high risk activities. Within this framework greater flexibility to voluntarily try out } \\
\text { new approaches and earned recognition would be welcomed, accommodated by good } \\
\text { relationships with regulators. Regulation that accommodates local decision making and } \\
\text { accountability necessary for flood management. }\end{array}$ \\
\hline
\end{tabular}

These results suggest the structure of the business sector, the capability and attitude towards compliance of its members, the degree of national and international competition and the degree to which regulations are tailored to the sector all play a part in shaping attitudes towards intervention. Further research would be required to reliably reveal preferences of industry sectors as a whole (e.g. as undertaken by Lüthi and Wüstenhagen for photovoltaic project developers) (Lüthi and Wüstenhagen, 2012). While case study organisations considered the choice of regulatory instrument to be an important aspect of regulatory design, other areas for improvement were also emphasised (Figure 1). 


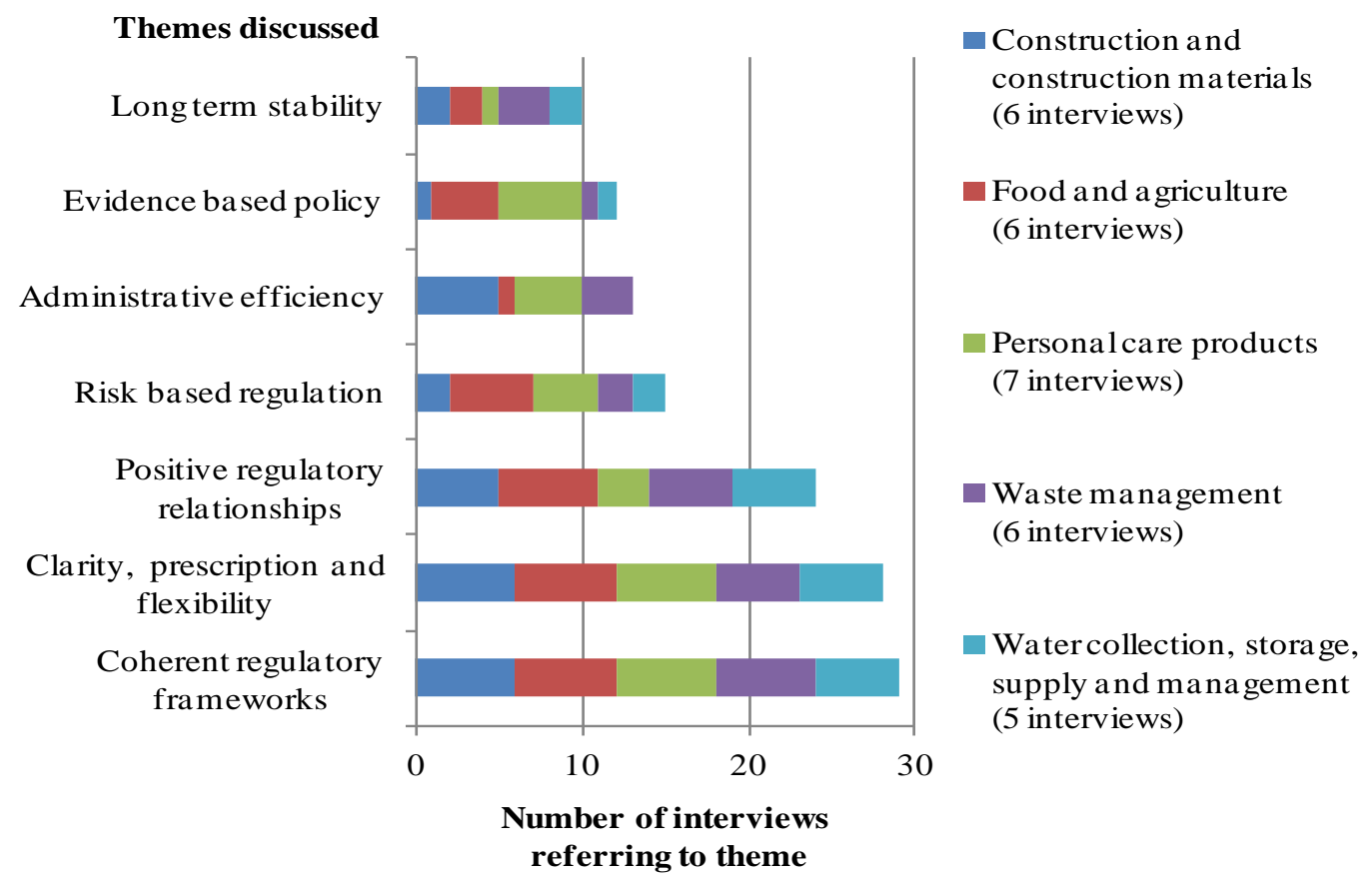

Figure 1. Themes in addition to instrument selection discussed by interviewees

\section{Coherent regulatory frameworks}

Incoherence in regulatory frameworks has been highlighted by others, where new regulations have been layered across existing regimes, nationally and internationally (Rayner and Howlett, 2009; UKELA, 2012). Nearly all participants in this study discussed coherence, providing evidence of its importance for effectiveness and efficiency. Coherent instruments support one another in a complementary mix. For example, construction site waste management plans (SWMPs) were thought to have encouraged builders to pay closer attention to waste streams, enhancing the impact of the Landfill Tax (The Landfill Tax (Amendment) Regulations 2013. SI 2013/658, 2013) and to have become incorporated into other construction standards. The Building Regulations (The Building (Amendment) Regulations 2013. SI 2013/1105, 2013) were argued to have enabled development of many supporting instruments, including third-party inspection and product labelling. Third party auditing of environmental performance has been relied upon to allow reduced inspections in 
high performing poultry farms (Defra, 2013a). Respondents emphasised the need for tailored interventions to cater for big and small businesses, and leading and poor performing businesses within a sector. The need for a mix of instruments to tackle critical points in supply chains was emphasised; for example, to ensure that good environmental performance is designed into construction projects from the outset. For waste recycling, respondents discussed the need for a mix of instruments along the waste stream; to increase producer responsibility for minimising waste and encouraging re-use; to provide coherent messages to consumers about what can be recycled; to improve the consistency and performance of recycling facilities between local authorities; and to provide confidence in the standard of recycled materials. For the water sector, influencing the upstream behaviour of individuals and businesses, for example in pesticide use or in the disposal of household products and pharmaceuticals down drains, was considered important alongside regulating water quality downstream, with the potential to reduce treatment costs.

Several respondents complained of inconsistent or overlapping requirements set by national bodies in various policy areas, including between planning permission and environmental permits for quarrying, in carbon reduction policies for construction, and in carbon reduction, waste treatment and water quality requirements for water companies. One respondent from the minerals industry argued that the primacy of the local land use and construction planning system, to make judgements that account for all local competing and influencing matters, had been undermined by the requirement for site-specific environmental permits. Similar issues were reported for international inconsistencies; for example, in the labelling of chemicals, or methods for carbon reporting set by different countries.

Overlapping requirements can arise among those set by industry; for example, for farms supplying multiple food retailers, each with their own set of standards. While some examples of coherent policy were highlighted (e.g. permitting of industrial installations, including 
incinerators; and building regulations), perceived incoherence was attributed typically to the failure of government to work together internationally, nationally or locally to reconcile conflicting objectives, or by deciding to implement new regimes rather than incorporate new requirements into existing frameworks. While governments have pursued various initiatives to improve integration (Gray et al., 2007; OECD, 2004), for these respondents there is scope to go further, which is likely to require better national and international integrated governance structures that encourage or force politicians, policy makers and regulators to coordinate better on policy and regulatory design (Rayner and Howlett, 2009).

\section{Clarity, prescription and flexibility}

Regulators have been encouraged to ensure rules are clearly articulated and easy to understand, so to increase effectiveness and reduce costs (Dutch Ministry of Justice, 2004; Hampton, 2005). Instruments that afford flexibility to businesses to decide how to achieve objectives encourage innovation and improve cost-efficiency, for example through "performance based standards" (Coglianese et al., 2002) or within voluntary agreements (Bressers and de Bruijn, 2005). However, greater flexibility may not be appropriate for firms with less resource to expend on designing measures for compliance, who may prefer prescriptive regulation that tells them what they need to do (Coglianese et al., 2002; Fairman and Yapp, 2005). The themes of clarity, prescription and the degree of flexibility left for innovation by the regulated are therefore intertwined and were often discussed together.

Most respondents discussed clarity in the design of regulatory instruments. Clear objectives were expected to lead to well designed instruments, the performance of which could be assessed easily. One respondent from the farming sector believed the Voluntary Initiative on pesticide use (Defra, 2006) was especially effective because requirements for spraying are clearly explained and readily applied. Two respondents from the construction 
industry agreed that the Oil Storage Regulations (The Control of Pollution (Oil Storage) (England) Regulations 2001. SI 2001/2954, 2001) were effective because requirements for storage bunding were easily communicated and checked. Respondents also sought clarity in definitions that delineate the boundaries of who is affected by regulations. One respondent described the introduction of permits for the operation of waste incinerators, which were clear in what operations were in scope and what would be required, enabling businesses to ensure compliance was achieved. In contrast, the definitions of what is meant by "waste", when deposition of material in the ground may be considered to be landscape "restoration" or waste "disposal", and what constitutes "incidental" contamination of inert waste or organic waste were highlighted as points of contention leading to uncertainty about compliance. However, other respondents called for greater flexibility and less prescription in regulatory instruments. Flexibility can accommodate local conditions; for example, to allow a local assessment of optimal biodiversity measures rather than standard requirements. For personal care products, flexibility was argued for to ensure expert judgement informed the safe levels of chemicals for the intended use of a product. The need for flexibility to accommodate process innovation in rapidly changing waste technologies, or improvements to water treatment operations was also emphasised. In the latter, regulations based on achieving outcomes (e.g. safe drinking water) rather than controlling inputs (e.g. specific water treatment technologies) were called for. Where instruments have clear high level objectives, but room for interpretation on how these should be achieved, agencies may choose or be required to provide clarifying guidance, which reportedly can allow the scope of regulations to creep beyond that originally intended (if guidance becomes treated as a regulatory requirement), and lead to inconsistency in regulatory decisions - both unwelcome among respondents. These results reinforce the need for the level of prescription and flexibility in regulation to be tailored to the capability of the target audience. Policy makers and regulators should 
carefully tailor the level of prescription in rules and guidance according to the capability of regulated industries to innovate effective solutions.

\section{Positive regulatory relationships}

While a body of research examines regulatory compliance and enforcement strategies (Gunningham, 2011), little research has focused on the relationship between regulatory officers and the regulated, although recent work in the US (Pautz and Wamsley, 2012; Pautz, 2010a, 2009) has provided empirical support for the observation (Lange and Gouldson, 2010) that mutual trust is necessary for modern forms of environmental governance. Respondents provided insight into how the quality of the relationship between regulator and regulatee affects how regulatees respond. For example, a farmer described improvements in the relationship with local regulators since they have become more open to farmers' needs beyond environmental protection objectives. Water sector respondents described close working relationships with regulators and government officials on long term planning issues, and welcomed opportunities to work together to take the sector forward. One commented: "Having a positive and pro-active relationship works well, as working together is as much about leadership principles as technical issues. Key to this is involvement and open dialogue from the outset, as this then engenders ownership and responsibility. What benefits all parties most is a mature relationship, and everything that goes with that maturity, rather than a parent and child relationship."

Respondents valued easy access to regulators to clarify requirements. However, where respondents believed regulators lacked understanding of their sector, or found decisions to lack transparency or accountability, this undermined working relationships. Several respondents complained of a lack of consistency between the decisions made by individual officers, between officers in different regions, and in one case between different 
countries, leading to additional effort to resolve decisions. Inconsistency was often linked to a lack of clarity in regulations, leaving too much scope for interpretation, and was most apparent to nationally operating businesses. Echoing previous research, these results suggest that trust may be undermined by regulatees' perceptions of inconsistency or lack of understanding among regulators, but that constructive working relationships have also been successfully established.

\section{Risk based regulation}

Scholars have examined various dimensions of risk based regulation for environmental protection, including strategic risk analysis by policy makers (Prpich et al., 2011), risk-based prioritisation of substances for regulation (Egeghy et al., 2011) and riskbased interventions by regulatory agencies (Gouldson et al., 2009). Respondents from all case study areas discussed the role of risk analysis in regulation, mostly for individual regulated sites. One argued the environmental permitting regime for industrial installations was successful as it provided for the determination, by the regulator, of the most appropriate emission limits on a site-specific basis. Respondents from the water sector argued there was scope to better target permit requirements on discharges from different types of source according to risk associated and local conditions. The need for risk-based inspections was highlighted by several respondents. In farming, the "earned recognition" approach (Defra, 2013a), which reduces inspections for good performing sites where other third party inspections are in place, was welcomed. However, one respondent argued that inspection was not generally risk-based and, instead, tended to target larger farms that performed well, while neglecting smaller farms that needed more support to improve compliance. Meanwhile, a waste management respondent applauded the efforts of regulators to target effort against waste criminals using proactive evidence-gathering and action. 
Some questioned whether the relative prioritisation of government policy areas was risk based arguing, for example, that regulatory effort should focus on the preservation of habitats rather than specific species, on food waste and other elements of sustainable consumption and production rather than carrier bags, and questioning whether the level of regulation for the water and waste industries were proportionate to their associated risks. In the personal care products sector, risk assessment of chemical components and mixtures is a central concern of direct regulations such as REACH as well as voluntary codes such as the International Fragrance Association (IFRA) standards. One respondent expressed concern that REACH was tending towards hazard rather than risk based regulation, resulting in regulatory effort from industry and government not focusing on exposures that presented the greatest risk. Uncertainty surrounding the impact of nanomaterials on the natural environment was highlighted by another respondent.

\section{Administrative efficiency}

The design of regulatory administrative systems was highlighted by several respondents as an important cause of irritation. For example, the Carbon Reduction Commitment Energy Efficiency Scheme, a hybrid instrument that originally incorporated an emissions trading system and performance league table, was thought by one respondent to have been effective in raising awareness of the costs of energy among managers, while two other respondents thought that it had been over-complex and that a simple tax would prove more effective. Regarding trading schemes, one respondent commented:

"They do seem to get terribly bogged down in definitional issues and trading arrangements and different exchanges and buy out clauses. To the extent where in almost all of the cases that I have worked on, the businesses affected end up saying, "Just give us a tax. We have to employ people just to try and account for our [trading scheme] exposure, or whatever. "...I 
must admit, as a policy person, I always liked the idea of trading schemes as a good thing and I thought it was good that the UK tended to do more of that than other countries. But it does seem, in practice, it gets very hard.".

Some respondents engaged in the planning system and the regulation of farming highlighted issues of unnecessary bureaucracy and "box ticking". Several respondents from the personal care products sector commented on the design of the EU REACH regulation, expressing the view that while the underlying principle of the regulation was good, the regulation is not well designed and in implementation has become excessively bureaucratic, although views on the severity of this problem varied. According to one respondent, similar issues can arise with voluntary approaches, commenting:

"I also tend to find, certainly at government and trade association level, perhaps with the company level, voluntary agreements seem to be just as time consuming and bureaucratic as traditional regulation. Whereas, obviously, the idea is that they are much more, sort of, light touch."

Three respondents from the waste industry saw potential in the use of information technology to improve regulatory efficiency, by making permit applications as "point and click" as possible, enabling information sharing with regulators through a web portal, and by developing a mobile phone app that could tell consumers whether particular materials could be recycled in their area.

These results support other research indicating that direct regulation and alternatives can impose significant administrative costs on participants (Dinica et al., 2007; Krarup and Ramesohl, 2002; Sovacool, 2011). While these costs need to be weighed against the wider social benefits of regulation, for participants in this study, poor implementation of administrative systems was a significant cause of concern. Recent government initiatives have sought to improve the ease with which regulatees can find out about and report on 
regulation (Defra, 2013b; Netherlands Government, 2013), and greater adoption of service design techniques such as “customer journey mapping” (Heapy and Parker, 2006; Macdonald et al., 2011) could prove beneficial, though its potential is under-researched.

\section{Evidence-based policy}

Scholars and governments have frequently called for policy to be evidence-based (Solesbury, 2001), and the brokering of scientific evidence that support's regulatory approvals featured in many interviews. One trade association described their role in gathering evidence to persuade local authorities and recycling businesses to recycle their members' products, so to meet their producer responsibility obligations. Another described gathering evidence on the carbon impact of their members' products, in anticipation of future scrutiny. Respondents from the personal care products sector discussed the central role of environmental and health risks in the regulation of chemicals. In general, where evidence for the beneficial environmental impact of regulation was lacking, respondents anticipated that businesses would be less willing to comply than when compelling evidence had been presented. One respondent argued that farmers would feel more motivated to tackle environmental problems when evidence was provided of local impacts, a view echoed by another who emphasised the importance of evidence to support the regulation of pesticides. Some respondents thought the UK government should review more systematically the effectiveness and efficiency of regulation, with one commenting:

"Businesses, private companies always put a lot of effort in to that process of doing project review and a post project assessment. Did you achieve what you set out to achieve? It's good business management. I don't think we have the same rigour with the decisions which are made by government on policy making and regulation." 
These results support the theory that normative motivations for compliance with regulation are significant among businesses (May, 2005; Winter and May, 2001) and link this motivation to the need for policy to be demonstrably evidence-based (Solesbury, 2001). They illustrate the role that regulatory actors can play in developing and brokering evidence to motivate action (Davies et al., 2010).

\section{Long-term stability}

Respondents from the waste management, construction and water industries emphasised the importance of long-term stability in the regulatory framework to enable businesses to invest in new infrastructure. The Landfill Tax, which provides a predictably escalating tax on putting waste to landfill, was considered to have been effective in providing businesses with the confidence to invest in alternative waste infrastructure. In the case of construction materials, the Building Regulations were argued to have provided long-term certainty in the objectives of government, for example regarding Zero Carbon Homes (Department for Communities and Local Government, 2013), while encouraging innovation through triennial reviews of product standards. In contrast, the respondent representing the views of suppliers to the water industry argued that the five-yearly review of water industry plans by regulators resulted in a cycle of "boom and bust" that raised the overall costs of water supply to consumers. These results echo the finance industry's calls for a "long, loud and legal" policy framework to encourage investment in renewable energy (UNEP SEFI, 2004), where long-term stability has been found to be a critical factor for policy effectiveness (Bürer and Wüstenhagen, 2009; Held et al., 2006). 


\section{Involving the business community}

Twenty-one respondents argued for the involvement of businesses in the design of regulatory frameworks from an early stage of development, to ensure their design is informed by a "real world" view of how regulations would work in practice, a perspective sometimes considered lacking among policy makers. As one respondent put it:

"So, that's why you get this disparity, I believe, of the real-life world because it's great that you sit in your office...typing some text as a regulation, but I really do believe that sometimes people need to get out in the real world, out of their office and, probably, out of their comfort zones and go and see things, what they mean and understand why maybe industry or whoever is complaining."

By ensuring this, respondents expected that businesses would contribute innovative ideas on how to meet environmental objectives, and that fewer problems would emerge later. Business involvement was expected to help ensure that where new regulation affects many different sectors (e.g. the water industry being affected by waste regulation), that the impact on all sectors is taken into account. Respondents also highlighted the risks of business involvement, including a loss of government independence, the possibility that design is unduly influenced by large businesses more so than SMEs, and that a repeated call for the clarification of requirements could lead to over-prescription. Effective cooperation between government and business requires mutual trust, which can be built through government demonstrating that it has listened to industry and by open engagement by officials and politicians who are willing to participate in open debate.

Researchers have found that voluntary agreements provide governments the opportunity to better understand and design interventions (Menanteau, 2003; Rezessy and Bertoldi, 2011). However, other stakeholders, including NGOs, may not welcome a closer relationship between industry and government, fearing regulatory capture (Pautz, 2010b) or 
loss of influence (Bomberg, 2007). The UK government has published best practice guidance for regulators to assess the impact of regulatory change (Department for Business Innovation and Skills, 2013c) placing significant emphasis on early business engagement, aspects of which are addressed through the Environment Agency's Regulated Business Forum and account management approach (Environment Agency, 2013). While it can be anticipated that respondents would welcome these measures, some of the concerns they raise regarding policy integration may require more profound reform, which may challenge the "integrative capacity" (Rayner and Howlett, 2009) of the UK government to realign existing regulatory frameworks.

\section{Role of trade associations}

Trade associations seek to influence policy development, providing regulatory advice to members, and working with government agencies to develop guidance tailored to industry characteristics. Often, trade associations establish technical committees that draw on member businesses to provide expert input to regulatory reform. Trade associations have also sought to educate politicians, the media and the general public about the environmental performance of their sectors. For example, one personal care products trade association described committing resources to informing the media about members' products to ensure debates about safety and environmental impact are informed by scientific evidence. Respondents described cases where trade associations have been able to establish environmental standards (e.g. British Retail Consortium packaging standards) and codes of practice (e.g. the Chemical Industries Association Responsible Care Programme), or to act as coordinating bodies for voluntary agreements (e.g. the National Farmers Union, among others, for the Campaign for the Farmed Environment). Trade associations around the world have played a central role in negotiating environmental agreements with governments on behalf of members (Bailey and 
Rupp, 2005) and in self-regulation (Lenox and Nash, 2003; Nash and Ehrenfeld, 1997). However, respondents noted the ability of trade associations to fulfil this role may be limited by factors such as competition law, the ability to establish standards that operated across national boundaries for businesses operating internationally, whether members were sufficiently similar (in size, and/or in business activities undertaken, and/or in levels of performance) to have closely aligned common interests, and the skills and resources of staff. Several respondents noted that SMEs may not be reached by industry-wide voluntary initiatives through this route.

\section{CONCLUSIONS}

\section{Implications for regulatory reform}

Considering the three research questions raised in the introduction above, the majority of industry representatives argued for a tailored mix of instruments to suit the economic and environmental context, rather than a preference for or against direct regulation. Those arguing for voluntary approaches prefer flexibility and support for business competitiveness; while those sceptical of voluntary approaches doubted their effectiveness and sought the level playing field offered by consistently-enforced direct regulation. The new evidence presented here supports calls for policy makers and regulators to choose instruments that are tailored to specific industry or business circumstances (Gunningham and Sinclair, 1999). However, instrument selection is only one aspect of regulatory reform. Our results suggest policy makers and regulators should also examine whether regulatory frameworks are coherent, balance clarity, prescription and flexibility, are enabled by positive regulatory relationships, are administratively efficient, targeted according to risk, evidence-based and are delivering long-term stability for regulated businesses. Failure to address these, which apply across the range of instruments, has the potential to undermine the effectiveness of environmental 
regulation, perhaps even to the extent that the expected benefits of careful instrument choice could be lost through poor implementation, as found by others (Testa et al., 2013). These responses have three important implications for regulatory reform and the onward development of the transition(s) required to deliver the required outcomes of reform, in practice.

1) Improving the coherence of environmental policy and regulation has become a priority in the eyes of most respondents, reflecting the gradual accumulation of new policy and regulatory instruments in the UK and EU over recent decades. Improving coherence will be necessary to deliver better regulation in the eyes of business.

2) In order to improve perceptions of coherence, policy makers and regulators need to examine the totality of regulation from the perspective of individual businesses or sectors, rather than approaching analysis and reform in the traditional silos of policy or regulatory responsibilities assigned by the legal and political system. Respondents are keen to engage in this process.

3) The analytical, institutional and political challenges of improving coherence need to be overcome, and incorporated into reform programmes (Department for Business Innovation and Skills, 2013b; Ladegaard et al., 2007). Policy analysis needs to reflect impacts on multiple sectors. Regional, national and international government institutions need to encourage policy makers and regulators to work together across organisational boundaries to coordinate design to improve "integrative capacity" (Rayner and Howlett, 2009). Political processes need to decide, rationally and fairly, on trade-offs between the interests of different sectors, and to incorporate measures to tackle emerging environmental risks without undermining the coherence of the existing regulatory framework. This seems a likely pre-requisite to improving the effectiveness, efficiency and fairness of regulatory frameworks in coming years. 
In terms of the practical aspects of making these transitions, a discussion is now underway on the implementation route towards smarter environmental regulation (e.g. see Defra, 2013b). The detail is beyond the scope of this paper, but it is clear that the consultations held to date have stimulated a valuable debate on the steps required. Among these are calls for simpler, transparent and streamlined communications with government; for a far more overt, riskbased rationale for regulatory interventions made fit-for purpose; and effective sanctions for those that continue to purposefully operate outwith regulatory norms. Future research challenges, especially for policy specialists, might consider the active monitoring of organisational behaviours as these reforms take shape.

Acknowledgements. We thank Edward Lockhart-Mummery and colleagues in Defra's Better Regulation Team for their support under Research Contract BR0101. CT was part-funded by an Engineering and Physical Sciences Research Council (EPSRC) Doctoral Training Account at Cranfield University. This research was co-funded Defra, EPSRC, the Natural Environment Research Council, and the Economic and Social Research Council (grant EP/G022682/1).

\section{REFERENCES}

Actal. About Actal. 2013. Available at: http://www.actal.nl/english/about-actal/. Accessed October $15,2013$.

Bailey I, Rupp S. Geography and climate policy: a comparative assessment of new environmental policy instruments in the UK and Germany. Geoforum 2005;36(3):387-401.

Bazeley P. Qualitative Data Analysis with NVIVO. 2nd ed. London: SAGE Publications; 2007.

Bomberg E. Policy learning in an enlarged European Union: Environmental NGOs and new policy instruments. J. Eur. Public Policy 2007;14(2):248-268.

Braathen NA. Instrument mixes for environmental policy: How many stones should be used to kill a bird? Int. Rev. Environ. Resour. Econ. 2007;1(2):185-235. 
Bressers H, de Bruijn T. Conditions for the success of negotiated agreements: partnerships for environmental improvement in the Netherlands. Bus. Strateg. Environ. 2005;14(4):241-254.

Bürer MJ, Wüstenhagen R. Which renewable energy policy is a venture capitalist's best friend? Empirical evidence from a survey of international cleantech investors. Energy Policy 2009;37(12):4997-5006.

Cabinet Office. About Red Tape Challenge. 2013. Available at: http://www.redtapechallenge.cabinetoffice.gov.uk/about/. Accessed December 4, 2013.

Coglianese C, Nash J, Olmstead T. Performance-Based Regulation: Prospects and Limitations in Health, Safety, and Environmental Protection. Harvard University: Regulatory Policy Program Report No. RPP-03.; 2002.

Davies GJ, Kendall G, Soane E, Li J, Charnley F, Pollard SJT. Regulators as "agents": Power and personality in risk regulation and a role for agent-based simulation. J. Risk Res. 2010;13(8):961982.

Defra. Evaluation of the Performance of the Voluntary Initiative for Pesticides in the United Kingdom - PS2009. Defra, London: Department for Environment, Food and Rural Affairs; 2006. Available at: http://sciencesearch.defra.gov.uk/Default.aspx $?$ Menu=Menu\&Module=More \&Location=None \& Completed=0\&ProjectID=14427. (Accessed: 5 April 2014).

Defra. Farming Regulation Task Force Implementation - Earned Recognition Plan. Defra, London; 2013a. Available at: https://www.gov.uk/government/publications/farming-regulation-task-forceimplementation-earned-recognition-plan. (Accessed: 5 April 2104).

Defra. Smarter Environmental Regulation Review: Phase 1 Report - Guidance and Information Obligations. Defra, London; 2013b. Available at: https://www.gov.uk/government/publications/smarter-environmental-regulation-review-phase-1report-guidance-and-information-obligations. (Accessed: 5 April 2014).

Department for Business Innovation and Skills. Using alternatives to regulation. 2013. Available at: https://www.gov.uk/government/policies/reducing-the-impact-of-regulation-onbusiness/supporting-pages/using-alternatives-to-regulation. Accessed October 15, $2013 \mathrm{a}$. 
Department for Business Innovation and Skills. Better Regulation Framework Manual - Practical Guidance for UK Government Officials, BIS/13/1038. Department for Business, Innovation and Skills, London; 2013b. Available at: https://www.gov.uk/government/publications/betterregulation-framework-manual. (Accessed: 5 April 2014).

Department for Business Innovation and Skills. Accountability for Regulator Impact - Guidance, BIS/13/1040. Department for Business, Innovation and Skills, London; 2013c. Available at: https://www.gov.uk/government/publications/regulator-impact-accountability-guidance. (Accessed: 5 April 2014).

Department for Communities and Local Government. Impact assessment - Next steps to zero carbon homes: Allowable Solutions. 2013. Available at: https://www.gov.uk/government/publications/next-steps-to-zero-carbon-homes-allowablesolutions. Accessed May 26, 2014.

Dinica V, Bressers HTA, de Bruijn T. The implementation of a multi-annual agreement for energy efficiency in The Netherlands. Energy Policy 2007;35(2):1196-1212.

Dutch Ministry of Justice. The "Table of Eleven”. A Versatile Tool. The Hague, Netherlands: Dutch Ministry of Justice; 2004.

Egeghy PP, Vallero DA, Hubal EAC. Exposure-based prioritization of chemicals for risk assessment. Environ. Sci. Policy 2011;14(8):950-964.

Environment Agency. Accountability for Regulator Impact and Business Engagement, LIT Code: 8510. Environment Agency, Bristol, U.K.; 2013. Available at: http://www.environmentagency.gov.uk/business/regulation/149256.aspx. (Accessed: 5 April 2014).

European Commission. General Report on REACH - COM(2013) 49 Final. European Commission, Brussels, Belgium; 2013. Available at: http://eurlex.europa.eu/LexUriServ/LexUriServ.do?uri=COM:2013:0049:FIN:EN:PDF. (Accessed: 5 April 2014).

European Parliament. Directive 2010/75/EU of the European Parliament and of the Council of 24 November 2010 on Industrial Emissions (integrated Pollution Prevention and Control). European Parliament, Brussels, Belgium and Luxembourg/Strasbourg, France; 2010. Available at: 
http://eur-lex.europa.eu/LexUriServ/LexUriServ.do?uri=OJ:L:2010:334:0017:0119:en:PDF. (Accessed: 5 April 2014).

Fairman R, Yapp C. Enforced Self-Regulation, Prescription, and Conceptions of Compliance within Small Businesses: The Impact of Enforcement. Law Policy 2005;27(4):491-519.

Gouldson A, Morton A, Pollard SJT. Better environmental regulation — contributions from riskbased decision-making. Sci. Total Environ. 2009;407(19):5283-5288.

Gray J, James T, Dickson J. Integrated regulation - experiences of IPPC in England and Wales. Water Environ. J. 2007;21(1):69-73.

Gunningham N, Sinclair D. Integrative regulation: A principle-based approach to environmental policy. Law Soc. Inq. 1999;24(4):853-896.

Gunningham N, Sinclair D. Leaders and Laggards. Next-Generation Environmental Regulation. Sheffield, UK: Greenleaf Publishing; 2002.

Gunningham N. Enforcing environmental regulation. J. Environ. Law 2011;23(2):169-201.

Hampton P. Reducing Administrative Burdens: Effective Inspection and Enforcement. H. M. Treasury, London; 2005.

Heapy J, Parker S. The Journey to The Interface. How Public Service Design Can Connect Users to Reform. London: DEMOS; 2006.

Held A, Haas R, Ragwitz M. On the Success of Policy Strategies for the Promotion of Electricity from Renewable Energy Sources in the EU. DG TREN, European Commission, Brussels, Belgium; 2006.

Howlett M, Rayner J. Design Principles for Policy Mixes: Cohesion and Coherence in "New Governance Arrangements.” Policy Soc. 2007;26(4):1-18.

Jordan A, Wurzel RKW, Zito A. The rise of "new" policy instruments in comparative perspective: Has governance eclipsed government? Polit. Stud. 2005;53(3):477-496.

Kelle U. Emergence vs. Forcing of Empirical Data? A Crucial Problem of Grounded Theory Reconsidered. Forum Qual. Sozialforsch. / Forum Qual. Soc. Res. 2005;6(2).

Krarup S, Ramesohl S. Voluntary agreements on energy efficiency in industry - Not a golden key, but another contribution to improve climate policy mixes. J. Clean. Prod. 2002;10(2):109-120. 
Ladegaard P, Djankov S, McLiesh C. Review of the Dutch Administrative Burden Reduction Programme. Washington, D.C., U.S.A.: World Bank Group; 2007.

Lange B, Gouldson A. Trust-based environmental regulation. Sci. Total Environ. 2010;408(22):52355243.

Lenox MJ, Nash J. Industry self-regulation and adverse selection: a comparison across four trade association programs. Bus. Strateg. Environ. 2003;12(6):343-356.

Lüthi S, Wüstenhagen R. The price of policy risk - Empirical insights from choice experiments with European photovoltaic project developers. Energy Econ. 2012;34(4):1001-1011.

Macdonald R, Donovan J, Percy R, et al. The Report of the Independent Farming Regulation Task Force. Defra, London; 2011.

May PJ, Winter S. Regulatory enforcement and compliance: Examining Danish agro-environmental policy. J. Policy Anal. Manag. 1999;18(4):625-651.

May PJ. Compliance Motivations: Perspectives of Farmers, Homebuilders, and Marine Facilities. Law Policy 2005;27(2):317-347.

Menanteau P. Can negotiated agreements replace efficiency standards as an instrument for transforming the electrical appliance market? Energy Policy 2003;31(9):827-835.

Miles MB, Huberman AM. Qualitative Data Analysis: An Expanded Sourcebook. 2nd ed. Thousand Oaks: SAGE Publications; 1994.

Nash J, Ehrenfeld J. Codes of Environmental Management Practice: Assessing Their Potential as a Tool for Change. Annu. Rev. Energy Environ. 1997;22(1):487.

Netherlands Government. Answers for business - Business File (Ondernemingsdossier). 2013;(09/18/2013). Available at: http://www.answersforbusiness.nl/regulation/company-dossier. Accessed November 29, 2013.

Obama B. Executive Order 13563 - Improving Regulation and Regulatory Review. The White House, Washington, D. C.; 2011a.

Obama B. Executive Order 13576 - Delivering an Efficient, Effective, and Accountable Government. The White House, Washington, D. C.; $2011 \mathrm{~b}$. 
OECD. OECD Environmental Performance Reviews: Sweden 2004. OECD, Paris, France: OECD; 2004.

OECD. Recommendation of the Council on Regulatory Policy and Governance. OECD, Paris, France: OECD; 2012.

Pautz MC, Wamsley CS. Pursuing Trust in Environmental Regulatory Interactions: The Significance of Inspectors' Interactions With the Regulated Community. Adm. Soc. 2012;44(7):853-884.

Pautz MC. Front-line regulators and their approach to environmental regulation in Southwest Ohio. Rev. Policy Res. 2010a;27(6):761-780.

Pautz MC. Environmental Reviews and Case Studies: Next-Generation Environmental Policy and the Implications for Environmental Inspectors: Are Fears of Regulatory Capture Warranted? Environ. Pract. 2010b;12(03):247-259. doi:10.1017/S1466046610000244.

Pautz MC. Trust between regulators and the regulated: A case study of environmental inspectors and facility personnel in Virginia. Polit. Policy 2009;37(5):1047-1072.

Prpich G, Evans J, Irving P, et al. Character of environmental harms: Overcoming implementation challenges with policy makers and regulators. Environ. Sci. Technol. 2011;45(23):9857-9865.

Rayner J, Howlett M. Conclusion: Governance arrangements and policy capacity for policy integration. Policy Soc. 2009;28(2):165-172.

Rayner S. How to eat an elephant: a bottom-up approach to climate policy. Clim. Policy 2010;10(6):615-621. doi:10.3763/cpol.2010.0138.

Rayner S. What drives environmental policy? Glob. Environ. Chang. 2006;16(1):4-6. Available at: http://www.sciencedirect.com/science/article/pii/S0959378005000749. Accessed January 15, 2014.

Rezessy S, Bertoldi P. Voluntary agreements in the field of energy efficiency and emission reduction: Review and analysis of experiences in the European Union. Energy Policy 2011;39(11):71217129.

Sevä M, Jagers SC. Inspecting environmental management from within: The role of street-level bureaucrats in environmental policy implementation. J. Environ. Manage. 2013;128:1060-1070. 
Solesbury WB. Evidence Based Policy: Whence It Came and Where It's Going. London: ESRC UK Centre for Evidence Based Policy and Practice, Queen Mary, University of London; 2001.

Sovacool BK. The policy challenges of tradable credits: A critical review of eight markets. Energy Policy 2011;39(2):575-585.

Sparrow MK. The Character of Harms: Operational Challenges in Control. Cambridge: Cambridge University Press; 2008.

Sparrow MK. The Regulatory Craft: Controlling Risks, Solving Problems, and Managing Compliance. Washington: The Brookings Institution; 2000.

Taylor C, Pollard S, Rocks S, Angus A. Selecting Policy Instruments for Better Environmental Regulation: a Critique and Future Research Agenda. Environ. Policy Gov. 2012;22(4):268-292. Taylor CM, Pollard SJT, Angus AJ, Rocks SA. Better by design: Rethinking interventions for better environmental regulation. Sci. Total Environ. 2013;447(0):488-499.

Testa F, Daddi T, De Giacomo MR, Iraldo F, Frey M. The effect of Integrated Pollution Prevention and Control regulation on facility performance. J. Clean. Prod. 2013.

The Building (Amendment) Regulations 2013. SI 2013/1105.

http://www.legislation.gov.uk/uksi/2013/1105/contents/made; 2013.

The Control of Pollution (Oil Storage) (England) Regulations 2001. SI 2001/2954. http://www.legislation.gov.uk/uksi/2001/2954/contents/made; 2001.

The Landfill Tax (Amendment) Regulations 2013. SI 2013/658. http://www.legislation.gov.uk/uksi/2013/658/contents/made; 2013.

Tribbia J, Moser SC. More than information: what coastal managers need to plan for climate change. Environ. Sci. Policy 2008;11(4):315-328. doi:10.1016/j.envsci.2008.01.003.

UKELA. The State of UK Environmental Law in 2011-2012. Is There a Case for Legislative Reform? Dorking, U.K.: UK Environmental Law Association; 2012. Available at: http://www.ukela.org/content/page/3006/Final report UK Environmental Law in 2011-2012.pdf. (Accessed: 5 April 2014). 
UNEP SEFI. Communiqué from Creating the Climate for Change, Sustainable Energy Finance, Bonn, Germany, 1-2 June 2004. UNEP, Nairobi, Kenya: UNEP SEFI; 2004. Available at: http://sefi.unep.org/fileadmin/media/sefi/docs/sef_communique.pdf.

US Environmental Protection Agency. Regulatory Development and Retrospective Review Tracker. 2014. Available at: http://yosemite.epa.gov/opei/RuleGate.nsf. Accessed January 15, 2014.

Winter SC, May PJ. Motivation for Compliance with Environmental Regulations. J. Policy Anal. Manag. 2001;20(4):675-698.

Yin RK. Case Study Research: Design and Methods. 4th ed. Los Angeles, U. S. A.: SAGE Publications; 2009. 